\title{
MODELING AND ANALYSIS OF AN ELECTRIC VEHICLE USING PAMVEC
}

\author{
S. C. A. de Almeida, \\ and F. L. A. Vieira \\ Universidade Federal do Rio de Janeiro \\ COPPE/UFRJ \\ Departamento de Engenharia Mecânica \\ CP. 68503, Rio de Janeiro, RJ, Brasi \\ CEP 21941-972 \\ silvioa@gmail.com \\ felipeangelim@poli.ufrj.br \\ Received: June 14, 2018 \\ Revised: August 20, 2018 \\ Accepted: October 26, 2018 \\ consumption \\ $\mathrm{C}_{\mathrm{D}} \quad$ drag coefficient, dimensionless \\ $\mathrm{C}_{\mathrm{RR}} \quad$ rolling resistance coefficient, dimensionless \\ $\mathrm{K}_{\text {struct }}$ structural mass factor, dimensionless \\ $\mathrm{M}_{\text {bat }} \quad$ battery pack mass, $\mathrm{kg}$ \\ $\mathrm{M}_{\text {trans }} \quad$ transmission mass, $\mathrm{kg}$
}

Keywords: electric vehicles; advanced automotive batteries; energy
ABSTRACT

Electric vehicles are considered a key technology to reduce fossil fuel consumption, emissions and energy consumption. However, Electric Vehicles require larger battery packs to reach acceptable range levels. The development of new batteries with higher specific energy could reduce the mass and the cost of Electric Vehicles and increase their driving range. This work analyzes the influence of battery specific energy on battery pack mass, energy consumption and the cost per kilometer of a Tesla Model S Electric Vehicle. The energy consumption and the cost per kilometer calculated were $0.221 \mathrm{kWh} / \mathrm{km}(22.1 \mathrm{kWh} / 100 \mathrm{~km})$ and $0.024 \mathrm{US} \$ / \mathrm{km}$ respectively.

\section{NOMENCLATURE}

$\mathrm{M}_{\text {curb }} \quad$ curb mass, $\mathrm{kg}$

$\mathrm{M}_{\text {glider }}$ glider mass, $\mathrm{kg}$

$\mathrm{M}_{\text {motor }}$ glider mass, $\mathrm{kg}$

\section{INTRODUCTION}

Electric Vehicles (EVs) have the potential to improve air quality and decrease fossil fuel dependence. EVs require larger battery packs (BPs) to reach acceptable range levels and high specific power capacities for acceleration, climbing, etc. Barriers such as limited driving range, high purchase cost and slow recharging time delay the mass adoption of these vehicles (Newbery et al., 2016; Franke et al., 2013; Ajanovic et al., 2016). The development of new batteries with higher specific energy could reduce the mass and the cost of EVs and increase their driving range.

Currently, the most commonly used batteries in EVs are Li-ion batteries, but other types of batteries are being developed, for example, $\mathrm{Li}$-sulfur and $\mathrm{Li}$ air batteries (Cosmin et al., 2013; Christensen et al.,
2011; Brutti et al., 2012). These new batteries present theoretical specific energy values from 4 to 10 times the current Li-ion specific energy (Song et al., 2013; Zhu et al., 2015).

This paper presents a modeling of a Tesla Model S EV and analyses the impact of the battery specific energy on BP mass, energy consumption and cost per kilometer. The Tesla Model S was chosen for this study due to its fast recharging time (the battery bank reaches $50 \%$ of full charge within 20 minutes), its global sales and due to the vehicle's high driving range when compared to other models on the market.

\section{METHODOLOGY}

In order to analyze the vehicle performance, the Parametric Analytical Model of Vehicle Energy Consumption (PAMVEC) was used (Simpson, 2005). PAMVEC is a modeling tool that allows users to compare the performance of different combinations of vehicle propulsion systems and fuels.

One of the main parameters affecting battery electric vehicles (BEVs) performance is their mass. The calculation of the mass of a BEV is described by the equation below:

$$
\begin{aligned}
M_{\text {curb }}=M_{\text {glider }}+ & K_{\text {struct }} \\
& \times\left(M_{\text {bat }}+M_{\text {motor }}+M_{\text {trans }}\right)
\end{aligned}
$$


where:

Mcurb is the curb mass;

Mglider is the glider mass;

Kstruct is the structural mass factor;

Mbat is the battery pack mass;

Mmotor is the electric motor mass;

Mtrans is the transmission mass.

The structural mass factor (Kstruct) is related to the structure that is necessary to endow the vehicle in order to support the propulsion system components. Electric motor mass, transmission mass and glider mass are given as inputs on PAMVEC.

The battery pack mass (Mbat) will be dimensioned to meet the energetic needs of the electric vehicle's driving range, electric motor power and accessory load.

The Tesla Model S RWD, $85 \mathrm{kWh} \mathrm{BP,} \mathrm{is}$ energized by Li-ion batteries manufactured by Panasonic (Menahem, 2014). The main characteristics of the modeled vehicle are described in Tab. 1.

Table 1. Inputs of Tesla Model S configuration.

\begin{tabular}{|c|c|}
\hline Platform Parameters & Value \\
\hline Glider mass $\left(\mathrm{m}_{\text {glider }}\right)$ & $1,474 \mathrm{~kg}$ \\
\hline Curb mass & $2,108 \mathrm{~kg}$ \\
\hline Drag coefficient $\left(\mathrm{C}_{\mathrm{D}}\right)$ & 0.24 \\
\hline Rolling resistance coefficient $\left(\mathrm{C}_{\mathrm{RR}}\right)$ & 0.007 \\
\hline Cargo mass (two persons) & $150 \mathrm{~kg}$ \\
\hline Accessory load & $1,000 \mathrm{~W}$ \\
\hline & \\
\hline Performance parameters & Value \\
\hline Acceleration: 0 to $100 \mathrm{~km} / \mathrm{h}$ & $5.6 \mathrm{~s}$ \\
\hline Top speed & $225 \mathrm{~km} / \mathrm{h}$ \\
\hline Driving range & $426 \mathrm{~km}$ \\
\hline & \\
\hline Powertrain & Value \\
\hline Electric çotor & $285 \mathrm{~kW}$ \\
\hline Lithium ion battery & Panasonic \\
\hline Specific energy & NCA18650 \\
\hline Energy density & $233 \mathrm{Wh} / \mathrm{kg}$ \\
\hline
\end{tabular}

\section{RESULTS AND DISCUSSION}

This paper presents a modeling of Tesla Model $\mathrm{S}$ and analyzes the impacts of driving range and the battery specific energy on battery pack mass, energy consumption and cost per kilometer. As discussed above, new batteries with higher specific energy could reduce the mass and cost of EVs and increase their driving range.

In order to analyze the vehicle performance, the Parametric Analytical Model of Vehicle Energy Consumption (PAMVEC) was used. PAMVEC predicts vehicle energy consumption on the basis of the driving cycle description, total vehicle mass and other inputs of the vehicle platform (such as drag coefficients and accessory loads) and the powertrain component characteristics and efficiencies.

\section{Battery pack mass and vehicle curb mass}

Figure 1 analyzes the influence of battery specific energy on the BP mass (Mbat) and on the vehicle curb mass (Mcurb). The green line (Ratio) shows the Mbat/Mcurb ratio. The dashed line (A) represents the specific energy of the original vehicle, Tesla Model S. The dashed line (B) represents the specific energy of a Li-sulfur battery reported by Song et al. (2013).

Figure 1 shows that battery specific energy has a significant influence on the vehicle mass. As can be noted in Fig. 1, for values up to $200 \mathrm{Wh} / \mathrm{kg}$, small variations in specific energy produce a strong change in the BP mass. For a battery specific energy of 200 $\mathrm{Wh} / \mathrm{kg}$, the BP mass, that attends to the energetic needs of the simulated vehicle, is $440 \mathrm{~kg}$. If the battery specific energy doubles $(400 \mathrm{Wh} / \mathrm{kg})$, the BP mass is reduced by $45.6 \%$, becoming $200 \mathrm{~kg}$. However, the reduction is less drastic for higher specific energy values: for an increase in the specific energy from $400 \mathrm{Wh} / \mathrm{kg}$ to $600 \mathrm{Wh} / \mathrm{kg}$, a reduction of $72 \mathrm{~kg}$ is achieved, i.e., approximately $35 \%$ of the BP mass.

\section{Energy consumption and cost per kilometer}

The effects of battery specific energy on vehicle energy consumption and cost per kilometer are showed in Fig. 2. The analysis of Fig. 2 shows that the higher the battery specific energy, the lower the energy consumption of the vehicle. This is due to the fact that a higher specific energy allows a lower battery mass and less energy is needed to power the vehicle.

Low energy consumption and high efficiency are two advantages of BEVs. These factors, associated with the low electricity cost in comparison to conventional fuels, result in a low cost per kilometer for BEVs.

According to the model developed with PAMVEC, for a battery specific energy of 233 $\mathrm{Wh} / \mathrm{kg}$, the energy consumption calculated is 0.221 $\mathrm{kWh} / \mathrm{km}(22.1 \mathrm{kWh} / 100 \mathrm{~km})$ and the cost per kilometer is $0.024 \mathrm{US} \$ / \mathrm{km}$ (2.4 US\$/100 km). Increasing the battery specific energy to $400 \mathrm{Wh} / \mathrm{kg}$ results in $0.207 \mathrm{kWh} / \mathrm{km}(20.7 \mathrm{kWh} / 100 \mathrm{~km})$ of energy consumption and in a cost per kilometer of $0.023 \mathrm{US} \$ / \mathrm{km}(2.3 \mathrm{US} \$ / 100 \mathrm{~km})$, i.e., about $5 \%$ lower.

EPA rates Tesla $\mathrm{S} 85 \mathrm{kWh}$ energy consumption at $24 \mathrm{kWh} / 100 \mathrm{~km}$ for a combined fuel economy (DOE, 2016). For purposes of comparison with conventional vehicles, the energy consumption of an internal combustion engine vehicle is approximately 0.60 $\mathrm{kWh} / \mathrm{km}$ (60 kWh/100 km) (Nylund, 2013). 


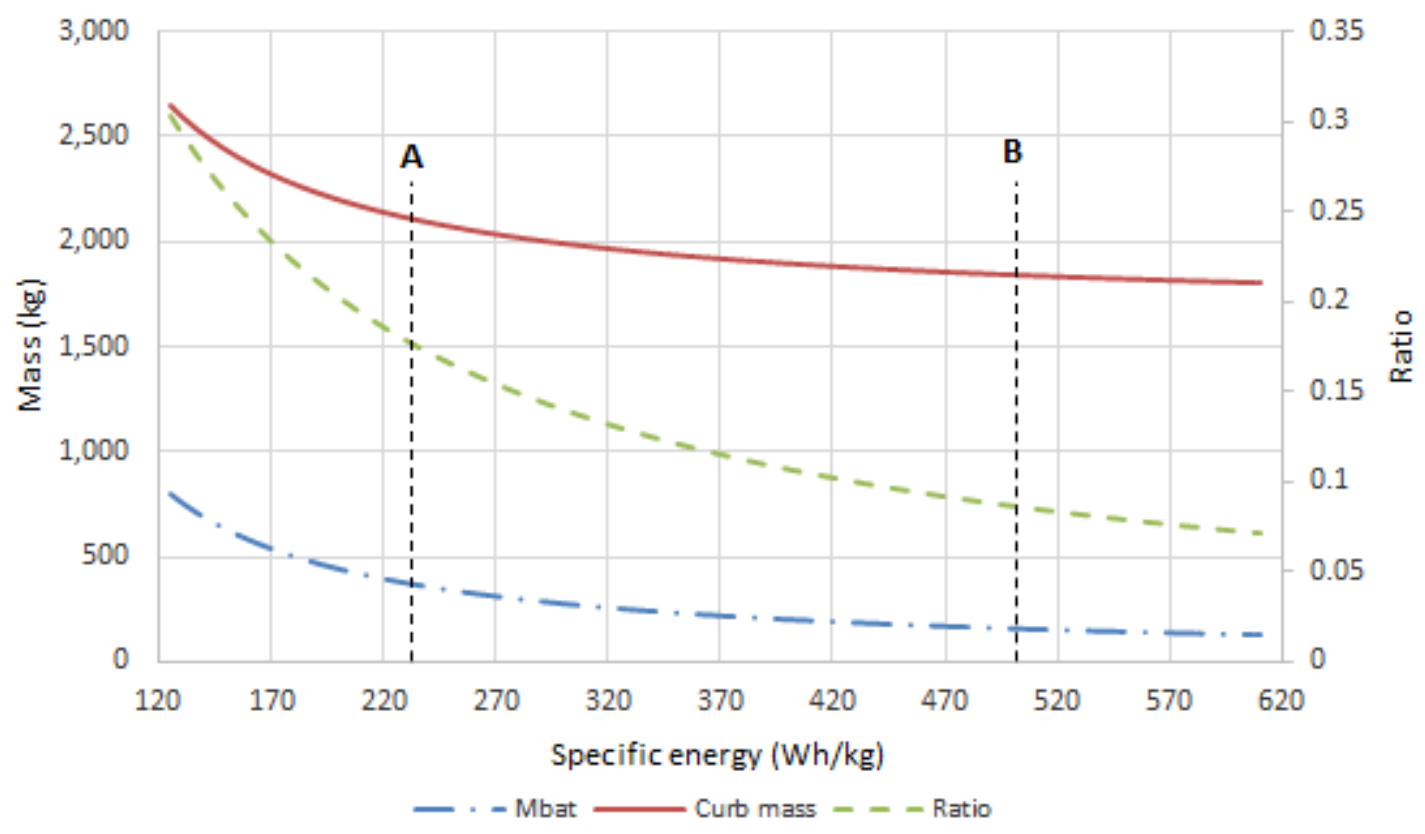

Figure 1. Battery pack mass and vehicle curb mass as a function of the battery specific energy of Tesla Model S.

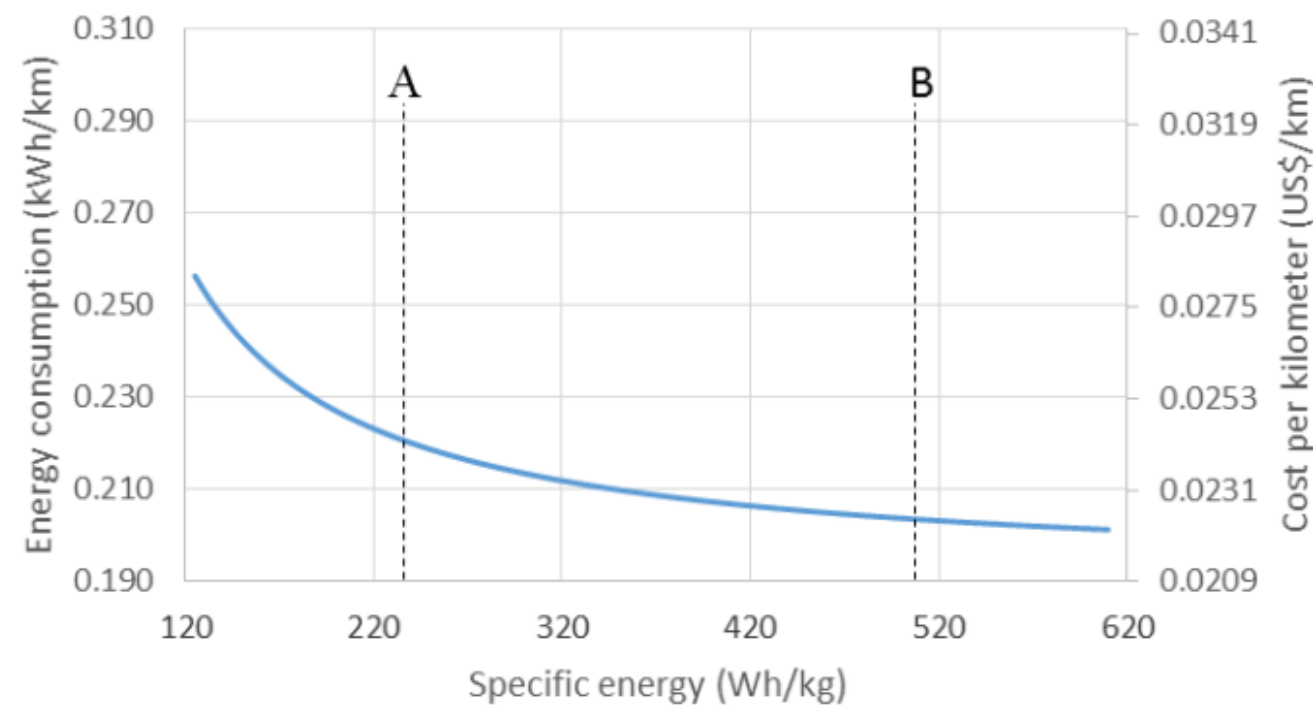

Figure 2. Influence of battery specific energy on energy consumption and cost per kilometer of the Tesla S.

\section{CONCLUSIONS}

According to the model developed with PAMVEC, the battery specific energy affects the curb mass, energy consumption and the cost per kilometer of a BEV. The higher the battery specific energy, the lower the BP mass, the energy consumption and the cost per kilometer.

There is a strong decrease in BP mass in low battery specific energy range (120-200 Wh/kg). In the range of high battery specific energy values $(\sim 500$ $\mathrm{Wh} / \mathrm{kg}$ ), the effect of increasing specific energy is more modest, leading to small reductions in mass.

The energy consumption calculated for Tesla Model S, energized by its original BP, is 0.221
$\mathrm{kWh} / \mathrm{kg}(22.1 \mathrm{kWh} / 100 \mathrm{~km})$ and the cost per kilometer is $0.024 \mathrm{US} \$ / \mathrm{km}$.

\section{REFERENCES}

Ajanovic, A., and Haas, R., 2016, Dissemination of Electric Vehicles in Urban Areas: Major Factors for Success, Energy, Vol. 115, pp. 1451-1458.

Brutti, S., Hassoun, J., Scrosati, B., and Lin, C. Y., 2012, A High Power Sn-C/C-LiFePO 4 Lithium Ion Battery, Journal of Power Sources, Vol. 217, pp. 72-76.

Christensen, J., Albertus, P., and SanchezCarrera, R. S., 2011, A Critical Review of Li/Air 
Batteries, Journal of the Electrochemical Society, Vol. 159, No 2, pp. R1-R30.

Cosmin, L., See, K., and Holman, K. M., 2013, Beyond Lithium-Ion: a Roadmap for NextGeneration Batteries, Report by Lux Research.

DOE, 2016, FY 2015 Annual Progress Report for Energy Storage $R \& D$, U. S. Department of Energy, Vehicle Technology Office.

Franke, T., and Krems, J. F., 2013, What Drives Range Preferences in Electric Vehicle Users?, Transport Policy, Vol. 30, pp. 56-62.

Menahem, A., 2014, Tesla Motors: battery Technology, Analysis of the Gigafactory, and the Automakers' Perspectives, Advanced Automotive Batteries.

Newbery, D., and Strbac, G., 2016, What is Needed for Battery Electric Vehicles to Become Socially Cost Competitive?, Economics of Transportation, Vol. 5, pp. 1-11.

Nylund, N., 2013, Mobility: technology

Priorities and Strategic Urban Planning, IEA EGRD Workshop.

Simpson, A. G., 2005, Parametric Modelling of Energy Consumption in Road Vehicles, Doctoral Thesis, Sustainable Energy Research Group, School of Information Technology and Electrical Engineering, University of Queensland, Australia.

Song, M., Zhang, Y., and Cairns, E. J., 2013, A Long-Life, High-Rate Lithium/Sulfur Cell: a Multifaceted Approach to Enhancing Cell Performance, Nano letters, Vol. 13, No. 12, pp. 58915899.

Zhu, X. B., Zhao, T. S., Wei, Z. H., Tan, P., and An, L., 2015, A High-Rate and Long Cycle Life Solid-State Lithium-Air Battery, Energy \& Environmental Science, Vol. 12, pp. 3745-3754. 